\title{
Comparison of PCR-based DNA fingerprinting techniques for the identification of Listeria species and their use for atypical Listeria isolates
}

\author{
Mario Vaneechoutte, ${ }^{1}$ Patrick Boerlin, ${ }^{2} \dagger$ Hans-Volker Tichy, ${ }^{3}$ \\ Elizabeth Bannerman, ${ }^{2}$ Birgit Jäger ${ }^{3}$ and Jacques Bille ${ }^{2}$
}

Author for correspondence: Mario Vaneechoutte. Tel: +32924036 92. Fax: + 3292403659. e-mail: Mario.Vaneechoutte@rug.ac.be

\footnotetext{
1 Department of Microbiology and Immunology, Blok A, University Hospital, 9000 Gent, Belgium

2 Swiss National Center for Listeriosis and WHO Collaborative Center for Foodborne Listeriosis, 1011 Lausanne, Switzerland

3 TÜV Energie und Systemtechnik $\mathrm{GmbH}$, Abteilung Biologische Sicherheit, Freiburg i. Br., Germany
}

\begin{abstract}
Four PCR-based DNA fingerprinting techniques were compared for their ability to identify at the species level a heterogeneous collection of isolates belonging to the six valid Listeria species. 165 rDNA-RFLP analysis identified all species and 16S rDNA-SSCP analysis identified almost all species. Also, isolates with unusual biochemical characteristics and/or unusual antigenic composition could be identified correctly. rRNA-intracistronic length polymorphism analysis suffered from high intraspecific variability, a limited number of fragments per profile, and small length differences between the spacers of different species. tRNA-intergenic length polymorphism analysis resulted in identification of all isolates but one, when fluorescent DNA capillary electrophoresis was used such that fragment length differences of 1 bp could be resolved. The four techniques yielded comparable results relevant to the taxonomy of Listeria. They all indicate a high degree of genetic relatedness between $L$. innocua and $L$. welshimeri, homogeneity of $L$. grayi, distinct but clear relatedness of $L$. grayi to the other Listeria species, a clear distinction between the two subspecies of $L$. ivanovii, and a clear distinction between Listeria isolates and isolates from closely related taxa or from species which are phenotypically difficult to distinguish from Listeria. New sequence determination of the 16S rRNA gene was necessary to obtain sequences in accordance with the findings of $16 \mathrm{~S}$ rDNA-RFLP analysis.
\end{abstract}

Keywords: Listeria, PCR-based DNA fingerprinting, 16S rDNA-RFLP, 16S rDNASSCP, spacer length polymorphism

\section{INTRODUCTION}

The genus Listeria is very homogeneous, except for $L$. grayi which is clearly distinct from the other species $(4$, $7,22,30,34)$. The taxonomy of the genus Listeria has been difficult to assess in the past, but molecular methods $(4,30,32)$ have clearly demonstrated the existence of six Listeria species (L. monocytogenes, $L$.

\footnotetext{
†Present address: Department of Pathobiology, University of Guelph, Guelph, Ontario, Canada N1G 2W1.

Abbreviations: ARDRA, amplified rDNA restriction analysis; SSCP, single strand conformational polymorphism.

The EMBL accession numbers for the sequences reported in this paper are X98526-X98532.
}

ivanovii, L. innocua, L. welshimeri, L. seeligeri and $L$. grayi). The former species ' $L$. murrayi' has been assigned to the species $L$. grayi (33). Only L. monocytogenes and $L$. ivanovii are recognized as significant pathogens of humans and animals. The Listeria species differ in only a few phenotypic characteristics $(12,22$, $31)$ and this high degree of similarity is the source of a lot of confusion in their identification. Furthermore, several other species, such as Bacillus species, Enterococcus species (particularly Enterococcus faecalis) and Cellulomonas (Oerskovia) turbata, are often misidentified as Listeria species by inexperienced microbiologists. Finally, the type strain of $L$. monocytogenes is phenotypically abnormal (23) and would be difficult to identify if it was encountered as a field isolate. 
Methods which combine the reliability of genotypic identification with the speed and simplicity of phenotypic methods such as biochemistry and serology, would be more than welcome, particularly in the presence of biochemically and serologically atypical isolates. Four PCR-based DNA fingerprinting methods have been described to enable identification of cultured bacterial organisms to the species level on the basis of genotype: rDNA-RFLP analysis (or ARDRA, amplified rDNA restriction analysis) and rDNA-single-strand conformational polymorphism (SSCP) analysis, which both make use of the speciesspecific sequence information in the 16S rRNA gene; and rDNA-spacer-PCR and tDNA-spacer-PCR, which have been reported to provide species-specific length polymorphism of rRNA intracistronic and tRNA-intergenic spacer regions, respectively. In this study we assessed the suitability of these four methods for the identification of the species of the genus Listeria.

ARDRA has been studied most thoroughly and has been used for the identification of species of different taxa, e.g. Acinetobacter (39), Clostridium (37), Comamonadaceae (41), Corynebacterium (40), Mollicutes (9), Mycobacterium (38), Leptospira (29) and Streptococcus (19), and to study phylogenetic relationships in Bacillus (16), Clostridium (13), Moraxella (18) and Xanthomonas (28).

Widjojoatmodjo et al. $(44,45)$ used SSCP analysis of part of the $16 \mathrm{~S}$ rDNA to identify a number of species, including all six Listeria species. Jensen et al. (20) showed that rDNA-spacer-PCR could be used to identify Escherichia species, some Enterobacter and Staphylococcus species and five of the six Listeria species ( $L$. seeligeri was not studied). Others used this approach successfully for the identification of Legionellaceae (17).

tDNA-spacer-PCR has been used for the identification of Staphylococcus species $(42,43)$, Streptococcus species (26) and Acinetobacter species $(10,46)$.

\section{METHODS}

Bacteria. Table 1 lists the isolates which were used. Besides representatives of all the six valid Listeria species, including the two subspecies of $L$. ivanovii (3), isolates of the species $L$. monocytogenes, $L$. innocua, $L$. welshimeri and $L$. ivanovii representing unusual biotypes or atypical antigenic compositions were also included and tested blindly. The Listeria isolates representing atypical biochemical or serological reactions were also tested with API-Listeria galleries (BioMérieux), following the recommendations of the manufacturer. Isolates of genera phylogenetically closely related to Listeria were also included since these may be phenotypically misidentified as Listeria.

Sample preparation for PCR. Target DNA was prepared from cells grown overnight at $37^{\circ} \mathrm{C}$ on Mueller-Hinton Agar II (MHAII; BBL Microbiology Systems) supplemented with $5 \%$ sheep blood. A $1 \mu \mathrm{l}$ volume of cells was suspended in $300 \mu \mathrm{l} 10 \mathrm{mM}$ Tricine $/ 1.5 \mathrm{mM} \mathrm{MgCl}{ }_{2}$ and heated at $100{ }^{\circ} \mathrm{C}$ for $10 \mathrm{~min}$ in a heating block. Five microlitres of the supernatant of this boiled cell suspension was used as the target DNA and was added - using filter-protected tips - to $45 \mu$ aliquots of PCR mix for all DNA fingerprinting techniques.

Amplification mixture. All reaction mixtures contained - at a final reaction volume of $50 \mu \mathrm{l}-0.005 \mathrm{U}$ Goldstar polymerase $\mu \mathrm{l}^{-1}$ (Eurogentec), $100 \mu \mathrm{M}$ each dNTP (Pharmacia Biotech) and $0 \cdot 2-0.5 \mu \mathrm{M}$ each primer in reaction buffer

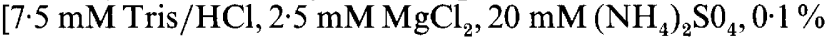
$(\mathrm{w} / \mathrm{v})$ Tween $20, \mathrm{pH} 9 \cdot 0]$. After aliquotting in $45 \mu \mathrm{l}$ volumes, mixtures were overlaid with $40 \mu \mathrm{l}$ mineral oil.

ARDRA. The 16S rRNA gene (16S rDNA) was amplified using $0.2 \mu \mathrm{M}$ primers complementary to conserved regions present at the edges of the 16S rDNA. The sequences of the primers were 5'TGGCTCAGATTGAACGCTGGCGGC (Escherichia coli nucleotide positions 10-27) and 5'TACCTTGTTACGACTTCACCCCA ( $E$. coli nucleotide positions 1507-1485). After initial denaturation at $95^{\circ} \mathrm{C}$ for $5 \mathrm{~min}$, the reaction mixtures were cycled 35 times for $45 \mathrm{~s}$ at $95^{\circ} \mathrm{C}, 45 \mathrm{~s}$ at $55^{\circ} \mathrm{C}$, and $1 \mathrm{~min}$ at $72^{\circ} \mathrm{C}$. Finally, a $7 \mathrm{~min}$ extension period at $72^{\circ} \mathrm{C}$ was carried out. The presence and yield of specific PCR products were determined by MultiPurpose (Boehringer) agarose $(1 \%, \mathrm{w} / \mathrm{v})$ - ethidium bromide $\left(50 \mathrm{ng} \mathrm{m}^{-1}\right)$ gel electrophoresis for 30 min at $7 \mathrm{~V} \mathrm{~cm}^{-1}$. Ten microlitre aliquots of the amplified DNA were used without further purification for restriction digestion. The following enzymes were used: $A l u \mathrm{I}, A v a \mathrm{I}, B a n \mathrm{I}, B f a \mathrm{I}$, Bsp1286I, BstEII, BstUI, CfoI (HhaI isoschizomer), DraI, EcoT38I, HaeIII, HinfI, MboI, MspI, MvaI, NciI, RsaI, Sau96I, ScrFI, StyI, TaqI and Tru9I. Restriction digestion was carried out for $1 \mathrm{~h}$ at $37^{\circ} \mathrm{C}$, except for TaqI and Tru9I, which were incubated at $65^{\circ} \mathrm{C}$, in $20 \mu$ l volumes of com-

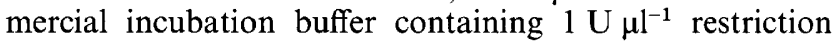
enzyme and $5 \mu \mathrm{l}$ amplified 16S rRNA gene product. Restriction fragments were separated by gel electrophoresis for $3 \mathrm{~h}$ at $7 \mathrm{~V} \mathrm{~cm}^{-1}$ on $3 \%$ Metaphor agarose (FMC BioProducts Europe) containing $50 \mathrm{ng}$ ethidium bromide $\mathrm{ml}^{-1}$.

16S rDNA-SSCP analysis. rDNA-SSCP analysis was carried out essentially as described by Widjojoatmodjo et al. (44). Primers P11P (5'GAG GAA GGT GGG GAT GAC GT) and P13P (5'AGG CCC GGG AAC GTA TTC AC) were used at concentrations of $0 \cdot 2 \mu \mathrm{M}$ to amplify a $216 \mathrm{bp}$ fragment of the V6 region of the 16S rDNA (E. coli $16 \mathrm{~S}$ rDNA positions 1175-1390). After initial denaturation at $95^{\circ} \mathrm{C}$ for $5 \mathrm{~min}$, the reaction mixtures were cycled 35 times for $20 \mathrm{~s}$ at $95^{\circ} \mathrm{C}, 1 \mathrm{~min}$ at $55^{\circ} \mathrm{C}$ and $1 \mathrm{~min}$ at $72^{\circ} \mathrm{C}$. Finally, a 7 min extension period at $72{ }^{\circ} \mathrm{C}$ was carried out: $0.3 \mu 1$ volumes of the amplification products were mixed with $6 \mu \mathrm{l}$ water and $3 \mu \mathrm{l}$ sequencing buffer ( $95 \%$ formamide, $20 \mathrm{mM}$ EDTA, $0.05 \%$ bromophenol blue and $0.05 \%$ xylene cyanol). The mixture was heated to $95^{\circ} \mathrm{C}$ for $5 \mathrm{~min}$ and loaded on the gels. The amplification products were separated in non-denaturing $0.5 \times$ MDE gels (FMC BioProducts) containing $5 \%$ glycerol. The gels were run overnight in a Protean II xi electrophoresis cell (Bio-Rad) in $0.5 \times$ TBE at room temperature at $90 \mathrm{~V}$. The gels were stained using the Silver Stain Plus kit (Bio-Rad) and the profiles were interpreted visually.

rRNA-intracistronic spacer length polymorphism analysis (rDNA-spacer-PCR). The intracistronic rDNA spacer regions were amplified by using primers - at concentrations of $0.5 \mu \mathrm{M}$ - flanking the $16 \mathrm{~S}-23 \mathrm{~S}$ rDNA spacer region (forward, 5'GAA GTC GTA ACA AGG; reverse, 5'CAA GGC ATC CAC CGT) (20). After initial denaturation at $95^{\circ} \mathrm{C}$ for $5 \mathrm{~min}$, the reaction mixtures were cycled 25 times for $1 \mathrm{~min}$ 
at $94{ }^{\circ} \mathrm{C}, 2 \mathrm{~min}$ at $55^{\circ} \mathrm{C}$, and $2 \mathrm{~min}$ at $72^{\circ} \mathrm{C}$, followed by a final $7 \mathrm{~min}$ extension period at $72{ }^{\circ} \mathrm{C}$. Twenty microlitres of each amplification product was separated in $4 \%$ polyacrylamide gels using $1 \times$ TBE at constant voltage in a Protean II xi electrophoresis cell. The gels were stained in a $1 \mu \mathrm{g}$ ethidium bromide $\mathrm{ml}^{-1}$ solution and photographed under short wavelength UV light. The migration profiles were compared visually.

tRNA-intergenic spacer length polymorphism analysis (tDNAspacer-PCR). tDNA-spacer-PCR was carried out essentially as described by Welsh \& McClelland (42). Primers T5A (5'AGT CCG GTG CTC TAA CCA ACT GAG) and T3B (5'AGG CCG CGG GTT CGA ATC C) were used at concentrations of $0.5 \mu \mathrm{M}$ to amplify the spacer regions between the tRNA genes. For analysis by capillary electrophoresis the T3B primer was labelled at the $5^{\prime}$ end with the fluorescent amidite TET (Applied Biosystems). After initial heating at $95^{\circ} \mathrm{C}$ for $7 \mathrm{~min}$, reaction mixtures were cycled 40 times for $30 \mathrm{~s}$ at $95^{\circ} \mathrm{C}, 30 \mathrm{~s}$ at $50^{\circ} \mathrm{C}$ and $2 \mathrm{~min}$ at $72{ }^{\circ} \mathrm{C}$, followed by final extension for $7 \mathrm{~min}$ at $72^{\circ} \mathrm{C}$. Capillary electrophoresis of fluorescently labelled PCR products was done on an ABI 310 (Applied Biosystems) using the POP-4 polymer and capillaries and with the TAMRA-500 standard as the internal lane size standard.

165 rDNA sequence determination. An approximately $1.45 \mathrm{~kb}$ segment of the 16S rRNA gene was amplified using primer 41 f (5'GCT CAG ATT GAA CGC TGG CG) and the biotin-labelled primer $1488 \mathrm{r}$ (5'biotin-CGG TTA CCT TGT TAC GAC TTC ACC). Forty microlitres of the PCR sample were added to Dynabeads M280 Streptavidin (Dynal), the DNA was denatured and the biotin-labelled single strand was immobilized onto the beads and used as one template for the sequencing reaction using fluorescent primers 358f (5' AGA CTC CTA CGG GAG GCA GCA GT), 536f [5' GTG CCA GC(AC) GCC GCG GTA ATA C] and $928 \mathrm{f}$ [ $5^{\prime}$ TAA AAC T(CT)A AA(GT) GAA TTG ACG GGG]. The opposite strand remaining in solution was also used as template using fluorescent primers 336r [5' ACT GCT GCS (CT)CC CGT AGG AGT CT] and 515r [5' G(AT)A TTA CCG CGG C(GT)GCTG GCA C]. Sequencing reaction products obtained by using the $\mathrm{T} 7$ Autoread kit (Pharmacia Biotech) were processed using an ALF DNA sequencer (Pharmacia Biotech) and the ALF manager software. DNA sequence comparisons were done using the HIBIO DNASIS software package (Hitachi). Published Listeria sequences were obtained from the EMBL database and the database included in the ARB package (see below). Tree construction was done using the ARB software package developed by Oliver Strunk, Wolfgang Ludwig and others from the Microbiology Department of the Technical University, Munich, Germany. The software version for Linux and the database (6aug9.ascii.arb) were obtained by anonymous ftp from ftp.biol.chemie.tu-muenchen.de.

Computer-assisted restriction analysis of the 16S rRNA gene was carried out with HIBIO DNASIS on EMBL sequences X56148-X56154 (7) and on the sequences obtained in the present work. Distance values were calculated using the neighbour-joining method with Kimura correction.

\section{RESULTS}

\section{ARDRA}

Restriction of the 16S rRNA gene was carried out with a total of 22 enzymes. Only restriction with $A l u \mathrm{I}$,

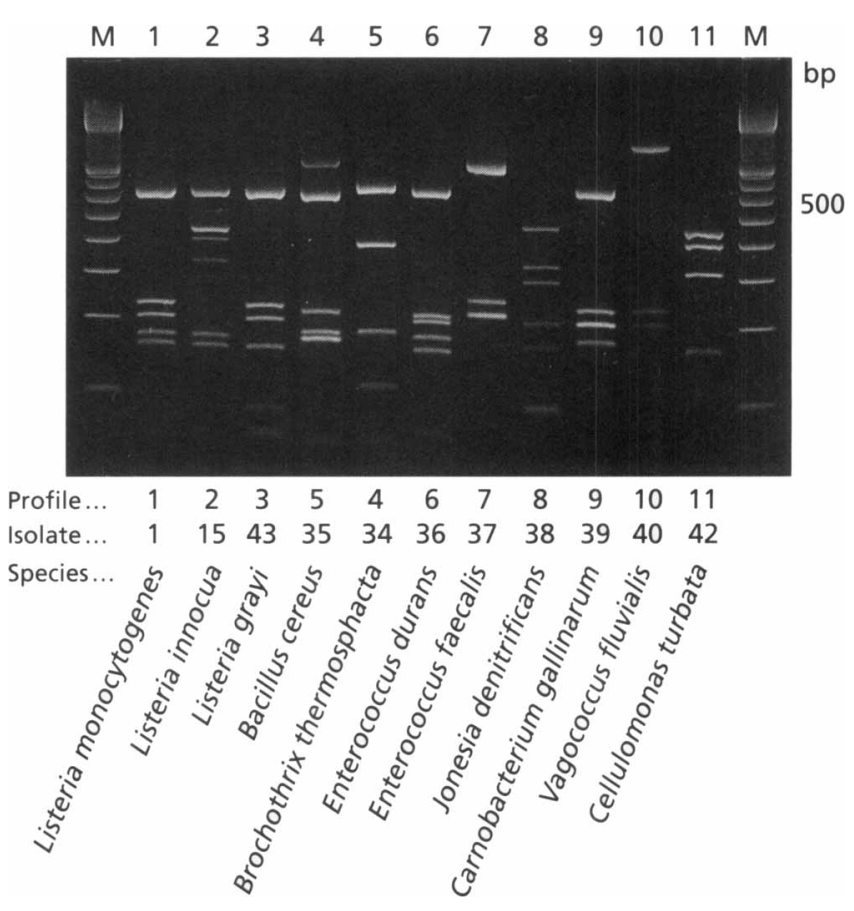

Fig. 1. 165 rDNA-RFLP profiles obtained by $3 \%$ agarose gel electrophoresis of digests of the amplified 16S rDNA after restriction with Alul.

Bst UI, CfoI, RsaI and Tru9I enabled some differentiation (Table 1). Combination of the profiles observed after digestion with $A l u \mathrm{I}$ (Fig. 1) and Bst $\mathrm{UI}$ enabled identification of all Listeria species, except for $L$. innocua and $L$. welshimeri, for which a constant difference could be shown only after restriction of the 16S rDNA with Tru9I (Table 1, Table 2). Also, only minor but constant differences could be observed for $B s t \mathrm{UI}$ restriction profiles of $L$. ivanovii subsp. ivanovii and $L$. ivanovii subsp. londoniensis, and for $L$. welshimeri and L. seeligeri (Table 2). L. grayi was clearly different from the other five species, since restriction with $A l u \mathrm{I}$ and $R s a \mathrm{I}$ yielded unique restriction profiles not observed for any other Listeria species (Table 1, Table 2). One L. innocua isolate (TI6520) had a BstUI profile (1c) with an additional $250 \mathrm{bp}$ fragment. For L. monocytogenes isolate IP11 an extra fragment was observed repeatedly in the $C f o \mathbf{I}$ profile. This could be resolved as the result of interference of minor non-specific amplification, not present in one of the collaborating laboratories. The isolates of the closely related non-Listeria species could easily be identified as such by restriction analysis of the $16 \mathrm{~S}$ rDNA, although some of the restriction enzymes yielded identical profiles for some Listeria and nonListeria species (Table 1).

16S rRNA gene sequence determination and phylogenetic tree construction for the genus Listeria

The sequences of the 16S rRNA genes were determined for seven isolates (indicated in Table 1). The distance 
Table 1. Designation of isolates, serotype and biotype, and of profiles observed for different PCR-based DNA fingerprinting techniques for species identification

\begin{tabular}{|c|c|c|c|c|c|c|c|c|c|c|}
\hline \multirow[t]{2}{*}{ Code } & \multirow[t]{2}{*}{ Original no. } & \multirow[t]{2}{*}{ Species* } & \multirow{2}{*}{$\begin{array}{l}\text { Serotype or unusual } \\
\text { agglutination reactions } \dagger\end{array}$} & \multicolumn{5}{|c|}{ ARDRA } & \multirow{2}{*}{$\begin{array}{c}\text { rDNA- } \\
\text { SSCP } \\
\text { analysis } \neq\end{array}$} & \multirow{2}{*}{$\begin{array}{l}\text { rDNA-spacer- } \\
\text { PCR }\end{array}$} \\
\hline & & & & AluI & Cfol & RsaI & BstUI & Tru9I & & \\
\hline 1 & LL195§ & L. monocytogenes & $4 \mathrm{~b}$ & 1 & 1 & 1 & la & $1 \mathrm{a}$ & 1 & 6 \\
\hline 2 & ZH7415 & L. monocytogenes & $1 / 2 \mathrm{a}$ & 1 & 1 & 1 & la & $1 \mathrm{a}$ & 1 & 4 \\
\hline 3 & SLCC2371 & L. monocytogenes & $1 / 2 \mathrm{a}$ & 1 & 1 & 1 & la & $\mathrm{ND}$ & 1 & 4 \\
\hline 4 & SLCC 2755 & L. monocytogenes & $1 / 2 \mathrm{~b}$ & 1 & 1 & 1 & la & $\mathrm{ND}$ & 1 & 5 \\
\hline 5 & SLCC2372 & L. monocytogenes & $1 / 2 \mathrm{c}$ & 1 & 1 & 1 & 1a & ND & 1 & 4 \\
\hline 6 & SLCC 2373 & L. monocytogenes & $3 a$ & 1 & 1 & 1 & 1a & ND & 1 & 4 \\
\hline 7 & SLCC 2540 & L. monocytogenes & $3 \mathrm{~b}$ & 1 & 1 & 1 & la & ND & 1 & 4 \\
\hline 8 & SLCC2479 & L. monocytogenes & $3 \mathrm{c}$ & 1 & 1 & 1 & $1 \mathrm{a}$ & $\mathrm{ND}$ & 1 & 4 \\
\hline 9 & SLCC2374 & L. monocytogenes & $4 a$ & 1 & 1 & 1 & $1 \mathrm{a}$ & la & 1 & 9 \\
\hline 10 & SLCC2375 & L. monocytogenes & $4 b$ & 1 & 1 & 1 & $1 \mathrm{a}$ & ND & 1 & 7 \\
\hline 11 & SLCC 2376 & L. monocytogenes & $4 c$ & 1 & 1 & 1 & 1a & ND & 1 & 10 \\
\hline 12 & SLCC 2377 & L. monocytogenes & $4 d$ & 1 & 1 & 1 & $1 \mathrm{a}$ & ND & 1 & 4 \\
\hline 13 & SLCC 2378 & L. monocytogenes & $4 e$ & 1 & 1 & 1 & $1 \mathrm{a}$ & ND & 1 & 6 \\
\hline 14 & SLCC 2482 & L. monocytogenes & 7 & 1 & 1 & 1 & 1a & ND & 1 & 5 \\
\hline 58 & IP11 & L. monocytogenes & V/VI;VI;VII;VIII;A;B;C & 1 & 1 & ND & la & la & 1 & 8 \\
\hline 59 & IP15 & L. monocytogenes & $4 \mathrm{~b}$ & 1 & 1 & ND & la & $\mathrm{ND}$ & 1 & ND \\
\hline 65 & NV3953 & L. monocytogenes & $1 / 2 b$ & 1 & 1 & $\mathrm{ND}$ & $1 \mathrm{a}$ & $\mathrm{ND}$ & 1 & ND \\
\hline 66 & NV4172 & L. monocytogenes ${ }^{\mathrm{b}}$ & $1 / 2 \mathrm{a}$ & 1 & 1 & $\mathrm{ND}$ & 1a & $\mathrm{ND}$ & 1 & ND \\
\hline 68 & LU4526 & L. monocytogenes ${ }^{c}$ & $4 b$ & 1 & 1 & ND & $1 \mathrm{a}$ & ND & 1 & ND \\
\hline 77 & BS6179 & L. monocytogenes ${ }^{\mathrm{c}}$ & $4 \mathrm{~b}$ & 1 & 1 & $\mathrm{ND}$ & $1 \mathrm{a}$ & ND & 1 & $\mathrm{ND}$ \\
\hline 79 & GE6366 & L. monocytogenes ${ }^{\mathrm{c}}$ & $1 / 2 \mathrm{c}$ & 1 & 1 & $\mathrm{ND}$ & 1a & ND & 1 & $\mathrm{ND}$ \\
\hline 15 & SLCC 3379/ATCC $33090 \S$ & L. innocua & $6 a$ & 2 & 1 & 1 & 1a & la & 2 & 13 \\
\hline 16 & LL271 & L. innocua & $6 \mathrm{~b}$ & 2 & 1 & 1 & 1a & la & 2 & 11 \\
\hline 17 & VD8304 & L. innocua & $6 a$ & 2 & 1 & 1 & $1 \mathrm{a}$ & 1a & 2 & 12 \\
\hline 18 & 8716 & L. innocua & $6 b$ & 2 & 1 & 1 & la & 1a & 2 & 11 \\
\hline 25 & VD7945 & L. innocua & $6 b$ & 2 & 1 & 1 & 1a & la & 2 & 11 \\
\hline 69 & GE5432 & L. innocua & $\mathrm{I} ; \mathrm{I} / \mathrm{II} ; \mathrm{A} ; \mathrm{B} ; \mathrm{C}(1 / 2 \mathrm{~b})$ & 2 & 1 & $\mathrm{ND}$ & $1 \mathrm{a}$ & 1a & 2 & $\mathrm{ND}$ \\
\hline 70 & GE5433 & L. innocua & $\mathrm{I} ; \mathrm{I} / \mathrm{II} ; \mathrm{A} ; \mathrm{B} ; \mathrm{C}(1 / 2 \mathrm{~b})$ & 2 & 1 & 1 & la & 1a & ND & ND \\
\hline 71 & TI5796 & L. innocua & V/VI;VII $; \mathrm{XV} ; \mathrm{B} ; \mathrm{C} ; \mathrm{D}$ & 2 & 1 & $\mathrm{ND}$ & $1 \mathrm{a}$ & 1a & 2 & ND \\
\hline 76 & VD6140 & L. innocua & V/VI;VII;XV;B;C;D & 2 & 1 & 1 & la & la & ND & ND \\
\hline 81 & Tl6520 & L. innocua & $\mathrm{XV} ; \mathrm{B} ; \mathrm{C} ; \mathrm{D}$ & 2 & 1 & ND & $1 \mathrm{c}$ & la & 2 & ND \\
\hline 82 & TI6551 & L. innocua & V/VI;VII;XV:B;C;D & 2 & 1 & 1 & la & 1a & ND & ND \\
\hline 83 & BL6621 & L. innocua & No somatic factors $\mathrm{A} ; \mathrm{B} ; \mathrm{C}$ & 2 & 1 & 1 & 1a & 1a & ND & $\mathrm{ND}$ \\
\hline 87 & BL6830 & L. innocua & VII;VIII;A;B;C & 2 & 1 & $\mathrm{ND}$ & la & 1a & 2 & ND \\
\hline 23 & SLCC $5334 \S$ & L. welshimeri & 6a & 2 & 1 & 1 & la & $\mathrm{lb}$ & 2 & 14 \\
\hline 24 & ZH7199 & L. welshimeri & $6 \mathrm{~b}$ & 2 & 1 & 1 & la & $1 \mathrm{~b}$ & $2+3$ & 14 \\
\hline 60 & LL244 & L. welshimeri & V/VI;VI;VII $; \mathrm{X} ; \mathrm{B} ; \mathrm{C} ; \mathrm{D}$ & 2 & 1 & $\mathrm{ND}$ & la & $1 b$ & $2+3$ & ND \\
\hline 61 & LL519 & L. welshimeri & $\mathrm{I} ; \mathrm{I} / \mathrm{II} ; \mathrm{A} ; \mathrm{B} ; \mathrm{C}(1 / 2 \mathrm{~b})$ & 2 & 1 & ND & la & $1 \mathrm{~b}$ & 2 & ND \\
\hline 62 & LL520 & L. welshimeri & $\mathrm{I} ; \mathrm{I} / \mathrm{II} ; \mathrm{A} ; \mathrm{B} ; \mathrm{C}(\mathrm{l} / 2 \mathrm{~b})$ & 2 & 1 & $\mathrm{ND}$ & la & $1 \mathrm{~b}$ & 2 & ND \\
\hline 63 & BS2094 & L. welshimeri & V/VI;VI;VII $; \mathrm{X} ; \mathrm{B} ; \mathrm{C} ; \mathrm{D}$ & 2 & 1 & $\mathrm{ND}$ & la & $1 \mathrm{~b}$ & $2+3$ & $\mathrm{ND}$ \\
\hline 67 & SO4352 & L. welshimeri & V/VI;VI:VII;X:B;C;D & 2 & 1 & 1 & $1 \mathrm{a}$ & $1 \mathrm{~b}$ & $\mathrm{ND}$ & ND \\
\hline 72 & TI5800 & L. welshimeri & V/VI;VI;VII $; \mathrm{X} ; \mathrm{B} ; \mathrm{C} ; \mathrm{D}$ & 2 & 1 & $\mathrm{ND}$ & $1 \mathrm{a}$ & $1 b$ & $2+3$ & ND \\
\hline 73 & GE5877 & L. welshimeri & V/VI;VI:VII;X:B;C;D & 2 & 1 & 1 & la & $1 b$ & $\mathrm{ND}$ & ND \\
\hline 74 & BE5963 & L. welshimeri & V/VI;VI:VII;X:B;C;D & 2 & 1 & 1 & $1 \mathrm{a}$ & $1 b$ & $\mathrm{ND}$ & ND \\
\hline 75 & BE6108 & L. welshimeri & V/VI; VI;VII;X; no H-factors & 2 & 1 & 1 & $1 \mathbf{a}$ & $1 \mathrm{~b}$ & ND & $\mathrm{ND}$ \\
\hline 78 & GE6254 & L. welshimeri & $\mathrm{V} / \mathrm{VI} ; \mathrm{VI}: \mathrm{VII} ; \mathrm{X}: \mathrm{B} ; \mathrm{C} ; \mathrm{D}$ & 2 & 1 & 1 & $1 \mathbf{a}$ & $1 \mathrm{~b}$ & $\mathrm{ND}$ & $\mathrm{ND}$ \\
\hline 84 & LU6662 & L. welshimeri & V/VI;VI $; \mathrm{VII} ; \mathrm{X} ; \mathrm{B} ; \mathrm{C} ; \mathrm{D}$ & 2 & 1 & ND & la & $1 b$ & $2+3$ & $\mathrm{ND}$ \\
\hline 85 & BE6112 & L. welshimeri & V/VI;VI:VII;X:B;C;D & 2 & 1 & 1 & 1a & $1 \mathrm{~b}$ & $\mathrm{ND}$ & ND \\
\hline 86 & AG7166 & L. welshimeri & V/VI;VI:VII $; \mathrm{X}: \mathrm{B} ; \mathrm{C} ; \mathrm{D}$ & 2 & 1 & 1 & $1 \mathrm{a}$ & $i b$ & ND & $\mathrm{ND}$ \\
\hline 19 & SLCC $3954 / A T C C C ~ 35967 \S$ & L. seeligeri & $1 / 2 b$ & 2 & 2 & 1 & $1 \mathrm{~b}$ & $1 \mathrm{a}$ & 3 & 3 \\
\hline 20 & 8375 & L. seeligeri & $4 a b$ & 2 & 2 & 1 & $1 \mathrm{~b}$ & la & 3 & 1 \\
\hline 21 & BE8950 & L. seeligeri & $1 / 2 b$ & 2 & 2 & 1 & $1 \mathrm{~b}$ & ND & 3 & 1 \\
\hline 22 & BE8953 & L. seeligeri & $4 d$ & 2 & 2 & 1 & $1 \mathrm{~b}$ & ND & 3 & 2 \\
\hline 64 & NV2918 & L. seeliger $t^{t^{1}}$ & $1 / 2 b$ & 2 & 2 & $\mathrm{ND}$ & $1 \mathrm{~b}$ & ND & 3 & ND \\
\hline 27 & LL278 & L. ivanovii subsp. ivanovii & 5 & 2 & 2 & 1 & $2 a$ & la & 6 & ND \\
\hline 28 & LL483 & L. ivanovii subsp. ivanovii & 5 & 2 & 2 & 1 & $2 a$ & la & 6 & 21 \\
\hline 29 & BE5087 & L. ivanovii subsp. ivanovii & 5 & 2 & 2 & 1 & $2 \mathrm{a}$ & ND & 6 & 21 \\
\hline 46 & CLIP12510T§ & L. ivanovii subsp. ivanovii & 5 & 2 & 2 & 1 & $2 \mathrm{a}$ & ND & 6 & 21 \\
\hline 51 & SLCC4306 & L. ivanovii subsp. ivanovii & 5 & 2 & 2 & 1 & $2 \mathrm{a}$ & ND & 6 & 20 \\
\hline 55 & SLCC2098 & L. ivanovii subsp. ivanovii & 5 & 2 & 2 & 1 & $2 \mathrm{a}$ & ND & 6 & 21 \\
\hline 30 & BE1604 & L. ivanovii subsp. londoniensis & 5 & 2 & 2 & 1 & $2 \mathrm{~b}$ & 1a & 4 & 19 \\
\hline 31 & BE5063 & L. ivanovii subsp. londoniensis & 5 & 2 & 2 & 1 & $2 \mathrm{~b}$ & la & $\mathrm{ND}$ & $\mathrm{ND}$ \\
\hline 32 & BE1694 & L. ivanovii subsp. londoniensis & 5 & 2 & 2 & 1 & $2 \mathrm{~b}$ & ND & 4 & $\mathrm{ND}$ \\
\hline 33 & BE3728 & L. ivanovii subsp. londoniensis & 5 & 2 & 2 & 1 & $2 b$ & ND & 4 & ND \\
\hline 47 & CLIP12229T§ & L. ivanovii subsp. londoniensis & 5 & 2 & 2 & 1 & $2 \mathrm{~b}$ & la & 4 & 18 \\
\hline 48 & BE5194 & L. ivanovii subsp. londoniensis & $\mathrm{I} ; \mathrm{I} / \mathrm{II} ; \mathrm{A} ; \mathrm{B} ; \mathrm{C}(1 / 2 \mathrm{~b})$ & 2 & 2 & 1 & $2 b$ & $\mathrm{ND}$ & 4 & ND \\
\hline 50 & BE5195 & L. ivanovii subsp. londoniensis & $\mathrm{I} / \mathrm{II}$;VII;no H-factors & 2 & 2 & 1 & $2 b$ & ND & $\mathrm{ND}$ & $\mathrm{ND}$ \\
\hline
\end{tabular}


Table 1 (cont.)

\begin{tabular}{|c|c|c|c|c|c|c|c|c|c|c|}
\hline \multirow[t]{2}{*}{ Code } & \multirow[t]{2}{*}{ Original no. } & \multirow[t]{2}{*}{ Species* } & \multirow{2}{*}{$\begin{array}{c}\text { Serotype or unusual } \\
\text { agglutination reactions; }\end{array}$} & \multicolumn{5}{|c|}{ ARDRA } & \multirow{2}{*}{$\begin{array}{c}\text { rDNA- } \\
\text { SSCP } \\
\text { analysis } \ddagger\end{array}$} & \multirow{2}{*}{$\begin{array}{l}\text { rDNA-spacer- } \\
\text { PCR }\end{array}$} \\
\hline & & & & $A l u \mathrm{I}$ & CfoI & RsaI & BstUI & TrugI & & \\
\hline 52 & CLIP2737 & L. ivanovii subsp. Iondoniensis & 5 & 2 & 2 & 1 & $2 \mathrm{~b}$ & $\mathrm{ND}$ & 4 & 19 \\
\hline 53 & $\mathrm{ZH} 7466$ & L. ivanovii subsp. londoniensis & $\mathrm{I} ; \mathrm{I} / \mathrm{II} ; \mathrm{A} ; \mathrm{B} ; \mathrm{C}(\mathrm{I} / 2 \mathrm{~b})$ & 2 & 2 & 1 & $2 \mathrm{~b}$ & ND & 4 & ND \\
\hline 43 & ATCC $25402 \|$ & L. grayi & & 3 & 2 & 2 & $2 a$ & 2 & 5 & 17 \\
\hline 44 & ATCC $25403 \|$ & L. grayi & & 3 & 2 & 2 & $2 \mathrm{a}$ & 2 & 5 & 15 \\
\hline 45 & SLCC2080/ATCC $19120 \S$ & L. grayi & & 3 & 2 & 2 & $2 a$ & ND & 5 & 16 \\
\hline 34 & LA3056 & Brochothrix thermosphacta & & 4 & 3 & 2 & 1 & ND & ND & ND \\
\hline 35 & LA3674 & Bacillus cereus & & 5 & 2 & 3 & $2 b$ & ND & ND & ND \\
\hline 39 & CIP $103610 \mathrm{~T}$ & Carnobacterium gallinarum & & 9 & 6 & 4 & 4 & ND & ND & ND \\
\hline 42 & LA3193 & Cellulomonas (Oerskovia) turbata & & 11 & 8 & 6 & 6 & ND & ND & ND \\
\hline 36 & LA2365 & Enterrococcus durans & & 6 & 4 & 4 & 4 & $\mathrm{ND}$ & $\mathrm{ND}$ & ND \\
\hline 37 & LA2390 & Enterococcus faecalis & & 7 & 4 & 4 & 4 & $\mathrm{ND}$ & $\mathrm{ND}$ & $\mathrm{ND}$ \\
\hline 38 & LA3225 & Jonesia (Listeria) denitrificans & & 8 & 5 & 5 & 5 & ND & ND & ND \\
\hline 40 & CIP $102976 \mathrm{~T}$ & Vagococcus fluvialis & & 10 & 7 & 4 & 3 & ND & ND & $\mathrm{ND}$ \\
\hline
\end{tabular}

ND, Not determined.

* Superscript letters indicate the following properties: a, arabitol-negative; b, L-rhamnose-negative; c, methyl $\alpha$-D-mannosidenegative; $d$, methyl $\alpha$-D-mannoside-positive.

$\dagger$ Serovar numbering and serological reactions are according to Seeliger \& Höhne (35). Serotypes with flagellar factors B;C;D or somatic factors VII;VIII or I;I/II; VII have not been described previously.

$\ddagger$ rDNA-SSCP analysis was at room temperature.

§Isolates of which the $16 \mathrm{~S}$ rRNA gene was sequenced in this study; their EMBL accession numbers are X98526-X98532.

$\|$ These isolates were formerly 'L. murrayi'.

values are given in Table 3 and a tree representation of this calculation is shown in Fig. 2. The sequences obtained in the present study differ from those obtained previously $(7,8)$. The number of differences (not counting undefined bases as differences and comparing with the best corresponding to previously published sequences for each species) was between 3 bp (with $L$. seeligeri sequence X56148) and 8 bp (with L. grayi sequence X56150). To construct a tree based on the 16S rRNA sequences of the Listeria species studied here, they were imported into the ARB package and aligned manually to match the alignment of the Listeria sequences determined previously $(7,8)$. A phylogenetic tree containing the published sequences and a combined tree containing also the sequences obtained in this study were constructed (data not shown). The clustering of the species in all three trees did not show significant differences. Thus, the sequence discrepancies found between published and new sequences had no influence on the determination of phylogenetic relationships, although there were less interspecific differences for the newly determined sequences. Computer-aided restriction digestion of the newly determined sequences corresponded perfectly with the observed ARDRA patterns, except for two minor discrepancies (Table 2).

\section{rDNA-SSCP analysis}

The results of the rDNA-SSCP analysis are reported in Table 1 and are illustrated in Fig. 3. Seven profiles were obtained for the six Listeria species examined. The profiles were composed of two or four bands. Five Listeria species and subspecies ( $L$. monocytogenes, $L$. seeligeri, L. ivanovii subsp. ivanovii, L. ivanovii subsp. londoniensis and L. grayi) had specific and homogeneous profiles. The eight $L$. welshimeri isolates presented two different profiles, and for three of these isolates this profile was identical to the unique $L$. innocua profile (Table 1). Electrophoresis was also performed under different conditions (four different buffer systems, electrophoresis at $6{ }^{\circ} \mathrm{C}$ or at room temperature, addition of 0 or $10 \%$ glycerol). The profiles obtained varied markedly, depending on the conditions used, but some or all $L$. welshimeri isolates remained indistinguishable from $L$. innocua, whereas differentiation of other species became difficult or impossible (data not shown).

\section{rDNA-spacer-PCR}

Analysis of the PCR products by PAGE showed that 21 profiles could be found among the 37 isolates tested (Fig. 4, Table 1). Several profiles were found within each species, except for $L$. welshimeri (for which only two isolates were tested). The profiles were composed of one main band and one or several minor bands. The variation within a species relied on both the minor and the main bands. Because of the variability within the species it was difficult to define reliable diagnostic criteria for species identification. rDNA-spacer-PCR was clearly reproducible. When repeating electrophoresis with new amplification products from the same strains, the same pofiles were obtained and the same differences between profiles were reproducibly detectable.

\section{tDNA-spacer-PCR}

The discriminatory power of tDNA-spacer-PCR depended highly on the resolving power of the electro- 


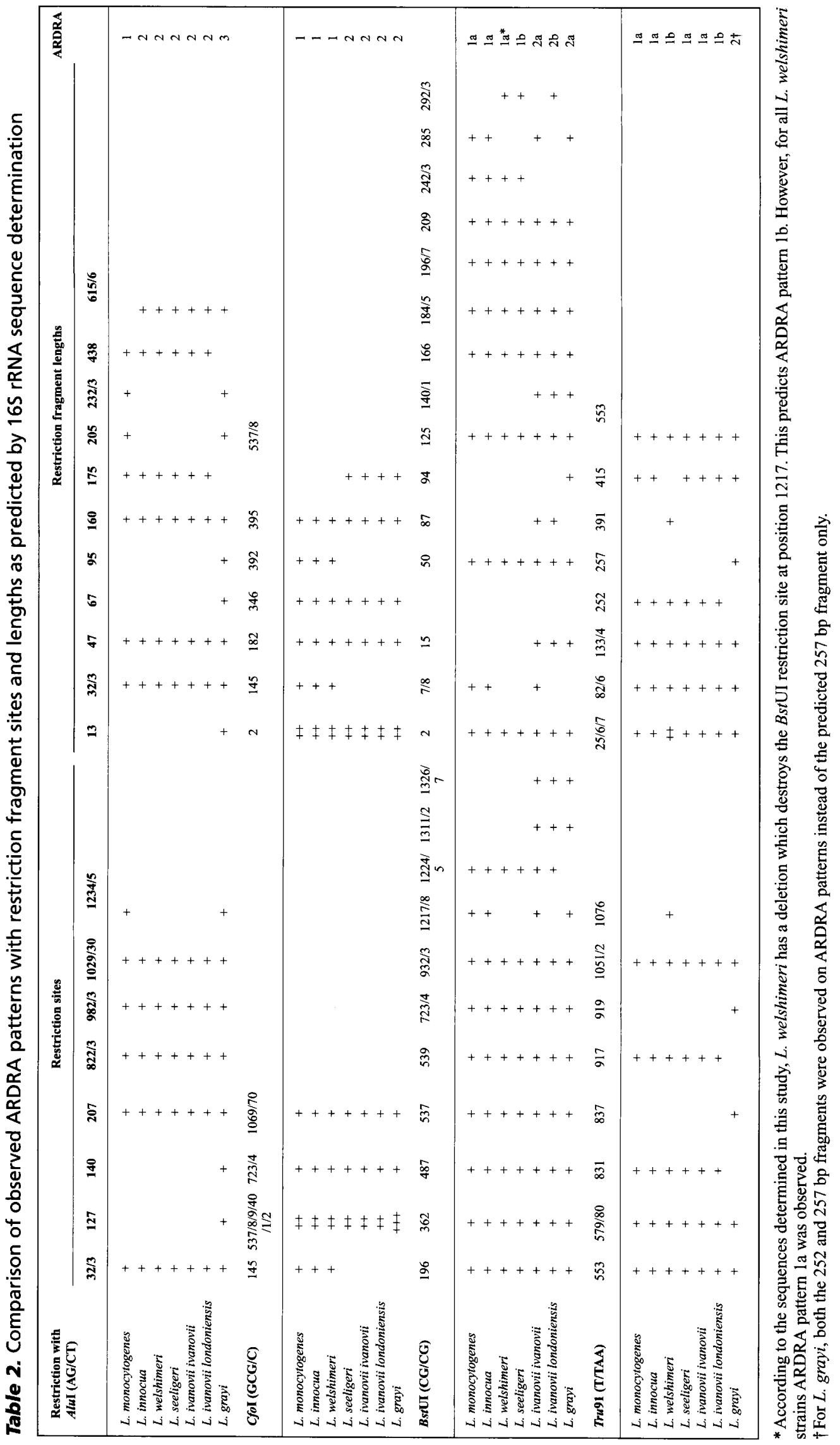


Table 3. Distance values data matrix of the Listeria 165 rRNA gene sequences determined in this work

Values were calculated using the neighbour-joining method (Kimura correction, vertical gaps compressed) provided by the ARB software package.

\begin{tabular}{|c|c|c|c|c|c|c|c|}
\hline & \multirow[t]{2}{*}{ L. grayi } & \multirow[t]{2}{*}{ L. innocua } & \multicolumn{2}{|c|}{ L. ivanovii subsp. } & \multirow[t]{2}{*}{ L. monocytogenes } & \multirow[t]{2}{*}{ L. seeligeri } & \multirow[t]{2}{*}{ L. welshimeri } \\
\hline & & & ivanovii & londoniensis & & & \\
\hline L. grayi & $0 \cdot 0000$ & 0.0424 & $0 \cdot 0348$ & 0.0393 & $0 \cdot 0386$ & 0.0393 & 0.0401 \\
\hline L. innocua & & 0.0000 & $0 \cdot 0100$ & 0.0093 & 0.0057 & 0.0071 & 0.0057 \\
\hline L. ivanovii subsp. ivanovii & & & $0 \cdot 0000$ & $0 \cdot 0035$ & $0 \cdot 0122$ & 0.0064 & 0.0100 \\
\hline L. ivanovii subsp. londoniensis & & & & 0.0000 & $0 \cdot 0136$ & $0 \cdot 0043$ & $0 \cdot 0085$ \\
\hline L. monocytogenes & & & & & $0 \cdot 0000$ & $0 \cdot 0114$ & $0 \cdot 0100$ \\
\hline L. seeligeri & & & & & & $0 \cdot 0000$ & 0.0057 \\
\hline L. welshimeri & & & & & & & 0.0000 \\
\hline
\end{tabular}

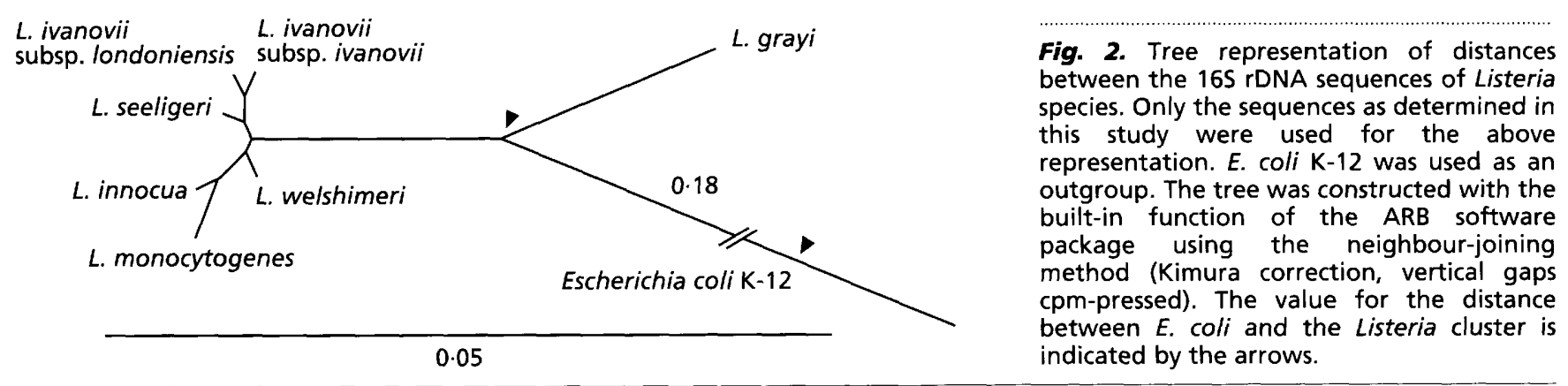

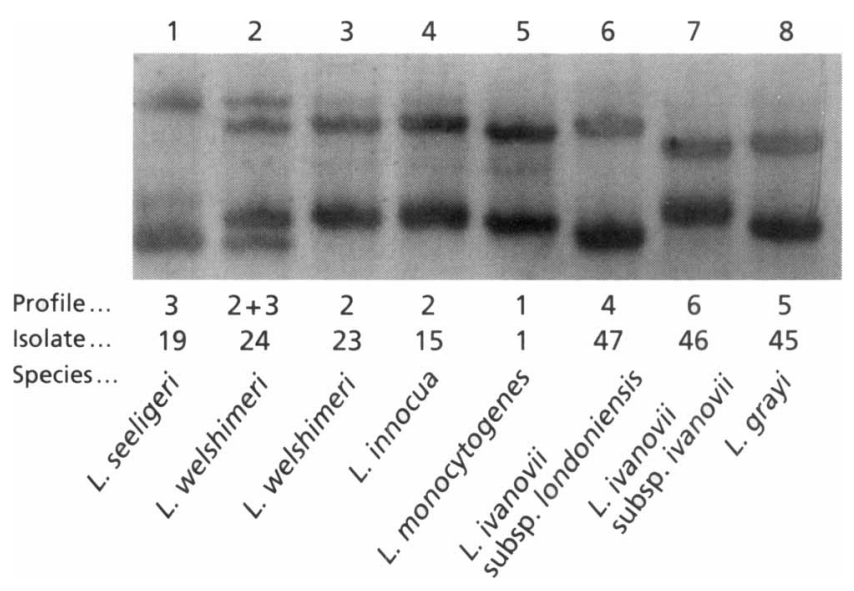

Fig. 3. SSCP profiles of an amplified 216 bp fragment of the $16 \mathrm{~S}$ rDNA as observed after an overnight run in non-denaturing $0.5 \times$ MDE gel in $0.5 \times \mathrm{TBE}+5 \%$ glycerol at room temperature at $90 \mathrm{~V}$ and silver staining.

phoresis technique used. Agarose gel electrophoresis and $5 \%$ PAGE were not sufficiently discriminatory for interpretation of the tDNA-spacer-PCR profiles (data not presented).

Only capillary electrophoresis provided sufficient resolution to yield useful results. Although substantial intraspecific differences were observed, several - interPCR and inter-electrophoresis run - reproducible differences between the species were present and enabled clustering into groups corresponding with established taxonomy (Table 4, Fig. 5). For instance, L. monocytogenes isolates were characterized by the presence of a 284,285 or $286 \mathrm{bp}$ peak, absent in all other isolates. Two L. monocytogenes isolates [SLCC 2374 (LIS9) and SLCC 2376 (LIS11)] lacked this peak, but could be differentiated from all other species by the presence of a 265 and a 267 bp peak (Fig. 5). L. innocua showed most intraspecific heterogeneity and had most peaks in common with $L$. monocytogenes, from which it could only be differentiated by the absence of the 284-286 and the $267 \mathrm{bp}$ peaks. The profile of one $L$. innocua isolate (TI6520) showed combined characteristics of L. innocua, L. welshimeri and L. monocytogenes profiles (Table 4 ), and thus, despite repeated testing, could not be identified. This is the same isolate with a slightly aberrant Bst UI restriction pattern (Table 1). All isolates of $L$. monocytogenes, L. innocua and $L$. welshimeri had a tRNA spacer of $159 \mathrm{bp}$, while this spacer was $160 \mathrm{bp}$ long for all $L$. seeligeri isolates and $162 \mathrm{bp}$ (with sometimes an additional $161 \mathrm{bp}$ peak) for all $L$. ivanovii isolates. The subspecies of the latter species could be differentiated by a single bp length difference of a tRNA spacer region of $85 \mathrm{bp}$ for L. ivanovii subsp. londoniensis and 86 bp for L. ivanovii subsp. ivanovii. Isolates of species other than Listeria had clearly different tDNA PCR profiles. 


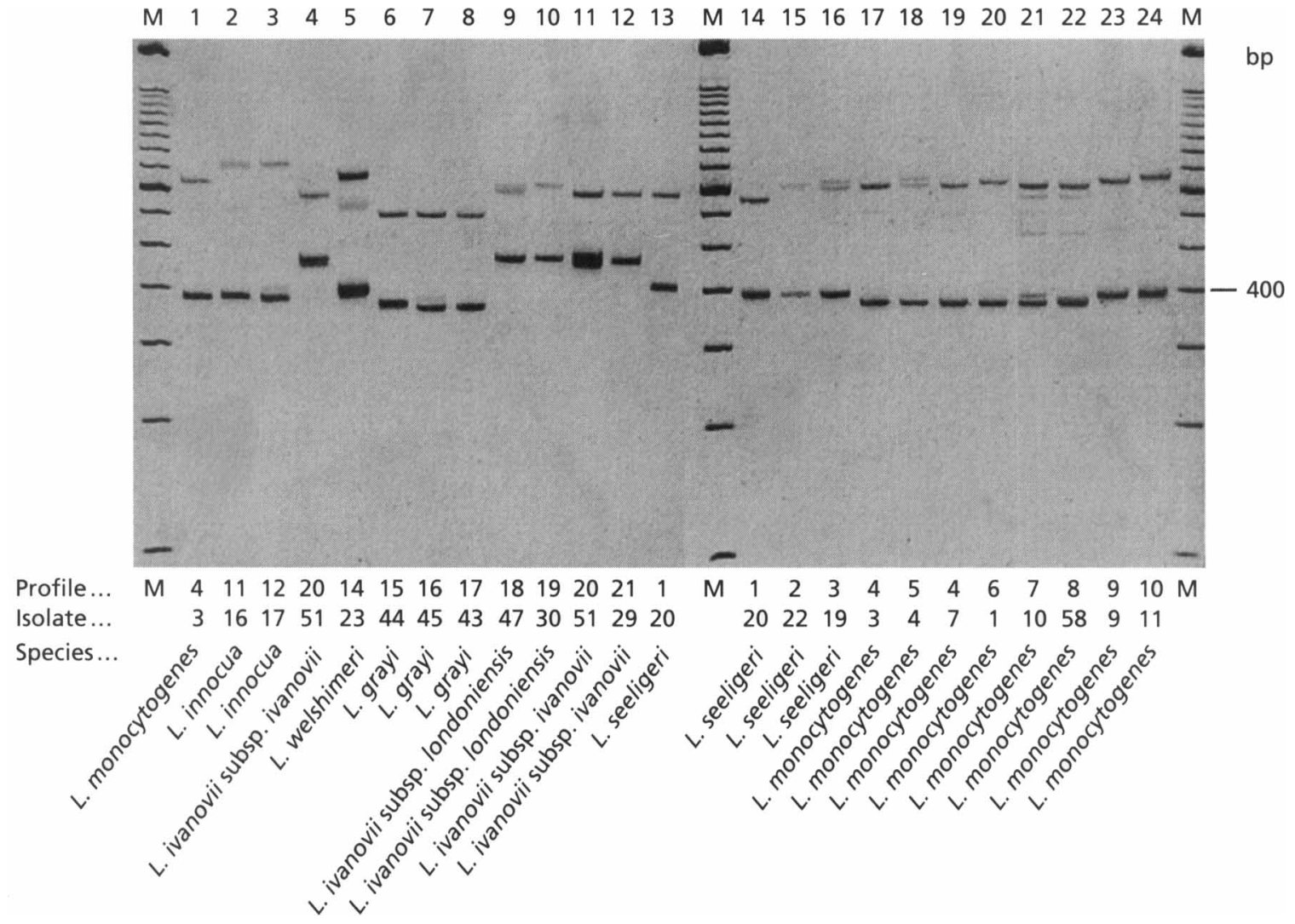

Fig. 4. rDNA-spacer-PCR profiles as observed after $5 \%$ PAGE and ethidium bromide staining (negative image).

For tDNA spacer amplification, reproducibility problems of the amplification step were observed. Upon analysis with agarose gel electrophoresis and PAGE, sometimes additional peaks were observed depending on the PCR run and relative peak height was variable between PCR runs (data not shown). Similar problems have been observed with e.g. arbitrarily primed PCR (36). However, highly identical profiles for different PCR runs were observed using capillary electrophoresis.

\section{Atypical isolates}

The molecular identification of atypical $L$. ivanovii subsp. londoniensis and of all the atypical L. monocytogenes and $L$. seeligeri using ARDRA, rDNASSCP analysis (Table 1), and tDNA-spacer-PCR analysed on capillary electrophoresis was in full agreement with the results obtained with the API galleries (Table 1). The phenotypically atypical $L$. innocua and $L$. welshimeri isolates could only be definitely identified by ARDRA and tDNA-spacerPCR.

\section{DISCUSSION}

Because of their high phenotypic similarity, only a limited number of biochemical tests can be used to differentiate the Listeria species from one another (31).
This is particularly true for $L$. monocytogenes and $L$. innocua, which must be clearly distinguished because of the health hazard represented by the former but not by the latter. However, both the haemolysis and the Christie-Atkins-Munch-Petersen (CAMP) test with Staphylococcus aureus, which are the distinctive criteria for these two species, are not always easy to interpret because some $L$. monocytogenes isolates produce only very faint haemolysis and/or weakly positive CAMP reaction. A positive CAMP reaction with Rhodococcus equi has recently been proposed as an additional identification criterion for $L$. monocytogenes (11). However, this test has long been controversial and has not been adopted by all laboratories. Its validity also heavily depends on the $R$. equi strain used for the reaction (11).

Several commercial galleries have recently been developed to make the identification of Listeria species easier $(1,2,24)$. Nevertheless, since some identifications still rely on a unique characteristic (2) for which some isolates may show an ambiguous reaction, additional tests like haemolysis and CAMP may still be necessary for a correct identification (24). Furthermore, biochemically abnormal isolates are regularly encountered during routine identification of Listeria isolates. Thus, in spite of tremendous improvements in commercial kits, phenotypic identification still remains difficult for a proportion of the isolates (1, 


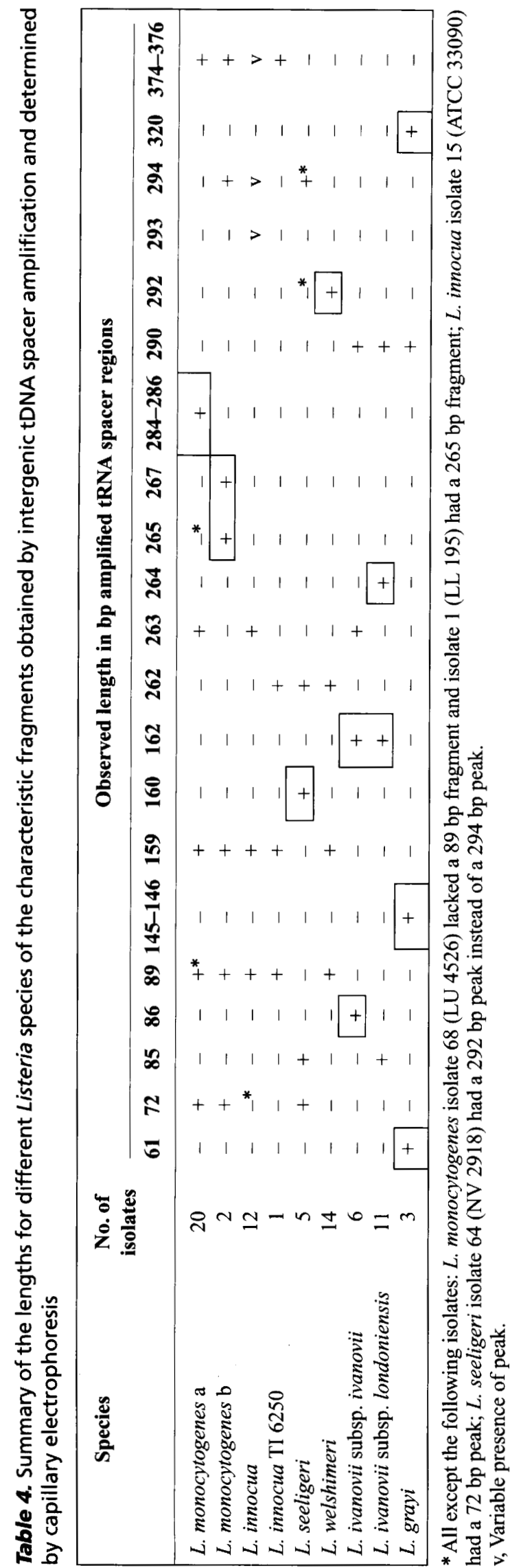

2). In such cases, rapid and reliable confirmation based on genetic criteria remains of great interest.

We evaluated the effectiveness of four of the PCR fingerprinting techniques for the identification of isolates of the genus Listeria. ARDRA enabled differentiation among all six species and between the two $L$. ivanovii subspecies, although only minor differences were detected between the non-haemolytic species $L$. innocua and $L$. welshimeri and between both $L$. ivanovii subspecies.

High discriminatory power was also obtained with rDNA-SSCP analysis (44), which identified all the Listeria species, except $L$. innocua and some $L$. welshimeri isolates, which shared indistinguishable profiles under several of the electrophoresis conditions tested. Since the sequences of the 16S rRNA gene regions amplified for SSCP analysis diverge at only one position for these two species, this lack of discrimination is not unexpected. A more recent study (45) showed that SSCP analysis of the rDNA required two different primer sets to differentiate all six Listeria species. Since six copies of the rRNA-operon are present in the genome of Listeria species (27), it is possible that the four bands observed in some of the $L$. welshimeri isolates rely on the simultaneous presence of two distinct alleles of the rRNA operon in the genome of these particular isolates.

Jensen et al. (20) reported that Listeria isolates can be identified on the basis of the sizes of the $16 \mathrm{~S}-23 \mathrm{~S}$ intracistronic rDNA spacers. The molecular sizes of the major fragments obtained by this method in the present work were approximately the same as those originally described. However, we found on several occasions differences in the banding profiles of isolates belonging to the same species, sometimes even in the major bands which have been suggested as diagnostic markers for species identification (Fig. 4). In our hands, this technique was therefore not useful for easy identification of the species of the genus Listeria, because of the lack of species-specific bands within the profiles of some species and because sometimes only minor electrophoretic migration differences were observed between profiles of different species. The reason for the discrepancy between both studies is not known, but the differences may be due to the use of different populations of Listeria isolates. Although we examined less isolates than Jensen et al. (20), the isolates used here were selected to cover a large spectrum of serotypes and may represent a more heterogeneous population than that used by these authors. Our results suggest that the sequence and length variability of the rDNA spacers may be greater than expected in the genus Listeria and that, as in other species $(5,14,15$, 25), rDNA-spacer-PCR may be used as a typing tool rather than an identification tool. Jensen \& Straus (21) pointed to the need for using special amplification conditions - i.e. low concentration of polymerase and polymerase buffer - to avoid multiple banding patterns. However, we obtained identical profiles when using these special conditions (data not shown). 


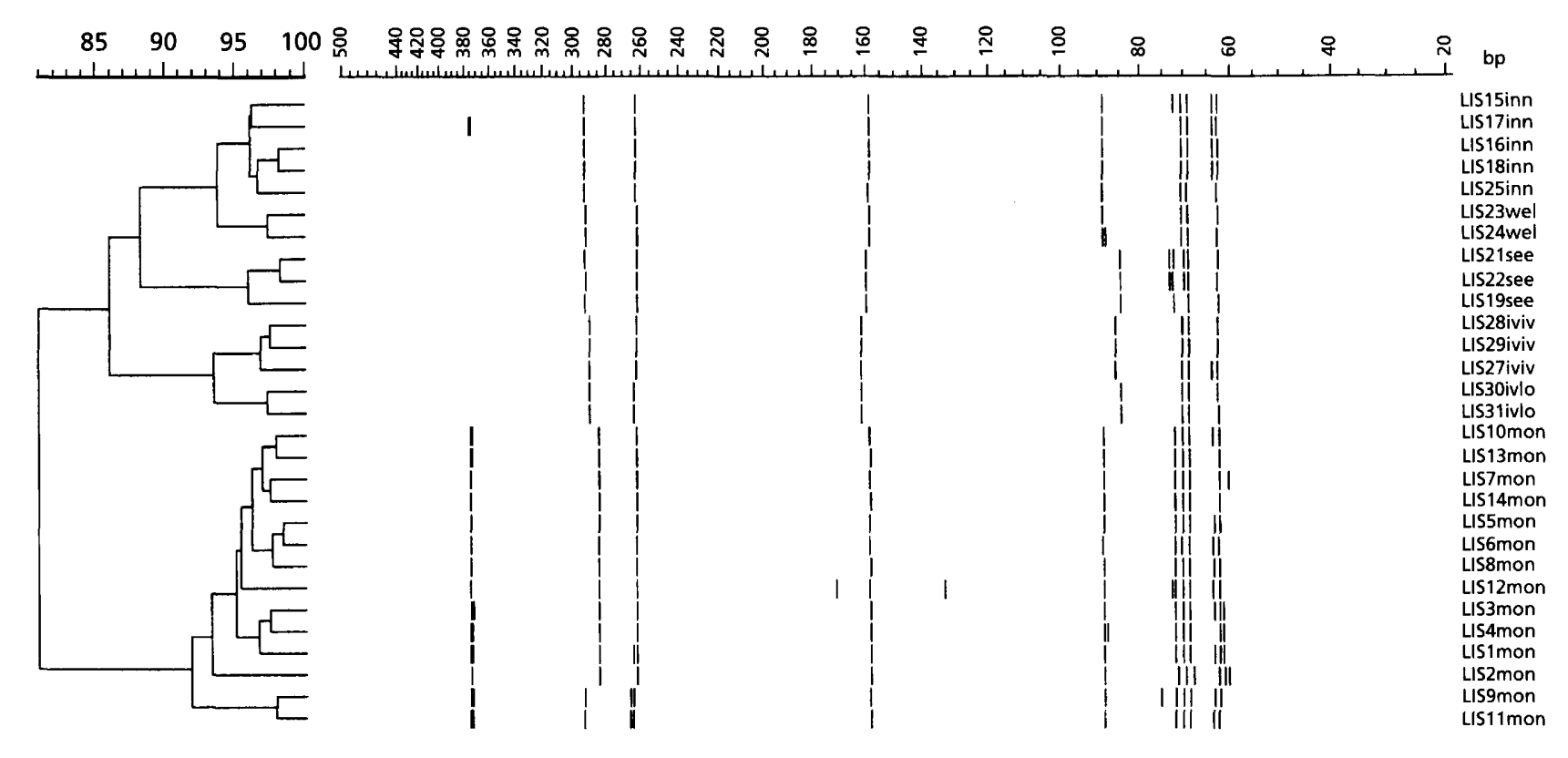

Fig. 5. Clustering with Ward algorithm of tDNA-spacer-PCR profiles obtained by capillary electrophoresis on an $A B I 310$ apparatus. Calculation of similarity matrix based on band-matching using area-sensitive coefficient (tolerance band position $0.1 \%$, minimal surface bands: $0 \%$ of total profile). Similarity indicated as a percentage on top of the dendrogram; fragment length of amplified tRNA spacers indicated in bp on top of fingerprints. Abbreviations of strain designations: inn, L. innocua; iviv, L. ivanovii subsp. ivanovii; ivlo, L. ivanovii subsp. londoniensis; mon, $L$. monocytogenes; see, L. seeligeri; wel, L. welshimeri. Numbers in the strain designation abbreviations refer to the study code as indicated in Table 1.

Capillary electrophoresis could reproducibly separate fragments differing by only a single base pair in length and only this high resolution enabled sufficient discrimination between the tDNA PCR profiles. Enhanced tDNA-PCR reproducibility by the use of capillary electrophoresis may be explained by the fact that the high resolution offered by this electrophoresis technique enables the detailed analysis of smaller sized fragments (basically in the range 60-300 bp), which may be more reproducibly amplified.

However, the subtlety of the observed differences, the peak height variability, the possible interference of background amplification products and the huge intraspecific variability (as was also observed with $5 \%$ PAGE) require careful evaluation of the practical applicability of tDNA-spacer-PCR. It can be concluded that thorough standardization of PCR conditions, high-resolution electrophoresis, and powerful pattern recognition and clustering software are needed to automate species identification based on tDNAspacer-PCR.

In addition to biochemical characterization, Listeria isolates may also be differentiated on the basis of their antigenic composition. Thirteen somatic antigens and five flagellar antigens have been described in the Listeria species and are currently used for serotyping (35). However, undescribed combinations of antigens are regularly encountered during serotyping of field isolates, several of which are listed in the present work. Some but not all serovars are species-specific. On one hand, $L$. ivanovii and $L$. grayi have species-specific antigenic combinations and the biochemically very close species $L$. monocytogenes and $L$. innocua do not share the same serovars and can therefore be differentiated serologically. On the other hand, L. seeligeri cannot be serologically distinguished from L. monocytogenes, nor can $L$. welshimeri be distinguished from L. innocua.

The species identification of 13 antigenically abnormal Listeria isolates (Table 1), as obtained with standard biochemical tests and with the API Listeria galleries, was confirmed by ARDRA, rDNA-SSCP analysis and tDNA spacer analysis. Among others, these data show that serovar 1/2b isolates can also be found in Listeria species other than $L$. monocytogenes and $L$. seeligeri (i.e. in L. innocua, L. ivanovii subsp. londoniensis and $L$. welshimeri) and consequently, that serotyping may not be as trustworthy, as is generally accepted, as a confirmatory tool for species identification. In addition, PCR-based DNA fingerprinting enabled the identification of four rarely encountered biochemical reaction patterns in $L$. monocytogenes and $L$. seeligeri (indicated as a-d in Table 1).

Because of discrepancies between 16S ARDRA results and computer-assisted restriction analysis of the published sequences $(7,8)$, the sequences of the $16 \mathrm{~S}$ rRNA genes of seven representative isolates were determined again. Computer-assisted restriction analysis of the sequences as determined in this study was almost in complete agreement with ARDRA results (Table 2), 
thus confirming the validity of the new updated rRNA gene sequences.

Besides possible sequencing errors, other reasons have been discussed previously (6) and may explain the discrepancies between the three independant $16 \mathrm{~S}$ rRNA gene sequence determinations carried out thus far $(7,8$, this study). Furthermore, application of reverse transcription prior to sequencing may be a major source of sequence errors.

The results obtained here with different PCR-based DNA fingerprinting techniques reflect the previously established high intragenic relatedness of the Listeria species. For example, for a total of 17 restriction enzymes out of 22 tested, not a single restriction site difference could be established in the 16S rDNA of the six species. Correspondingly, the new sequences presented here indicate that the dissimilarity estimates between the 16S rRNA genes of the different Listeria species are even lower than previously reported (7), although this does not influence the phylogenetic relatedness as has been established previously.

Subtle, but reproducible, differences between $L$. ivanovii subsp. ivanovii and $L$. ivanovii subsp. londoniensis could be established by several techniques. Sequence comparison of the first $1200 \mathrm{bp}$ of the $16 \mathrm{~S}$ rDNA revealed only two base pair substitutions (at positions 46 and 1096) between both subspecies, and single bp length differences were observed between tDNA spacers of isolates of both subspecies. These data fit the classification of the two corresponding genomic groups at the subspecies level (3) and not as different species. Only ARDRA and tRNA-spacerPCR could establish some differences between $L$. innocua and $L$. welshimeri. Interestingly, L. innocua and $L$. welshimeri also share common serotypes. $16 \mathrm{~S}$ rDNA sequence similarity distances as calculated here for the species pairs $L$. monocytogenes $-L$. innocua and $L$. welshimeri - L. innocua are comparable (Table $3)$. Finally, the fingerprints obtained for $L$. grayi differed most from those of all the other Listeria species, thus confirming its distance from the rest of the genus $(4,7,12,31)$. L. grayi was found to be homogeneous with all techniques (except with rDNAspacer-PCR), which is in agreement with the recent grouping of $L$. grayi and ' $L$. murrayi' into one unique species (33).

\section{Conclusions}

In conclusion, the previously published 16S rRNA gene sequences of all six Listeria species have been updated and now fit the restriction profiles obtained by ARDRA. In our hands, ARDRA performed best with respect to both discriminatory power and practical applicability. Satisfactory results were obtained with rDNA-SSCP analysis and tDNA-spacer-PCR, although the former requires thorough standardization of electrophoresis conditions and the use of additional primer sets, and the latter requires high-resolution electrophoresis. All of these techniques also allowed the reliable identification of biochemically and serologically atypical Listeria isolates. The data reported here confirm a high genetic relatedness between most Listeria species and suggest a closer relationship than expected between the two non-haemolytic species $L$. innocua and $L$. welshimeri, which also share common serotypes. The combination of the $16 \mathrm{~S}$ rDNA sequence data and the data gathered with the different PCR fingerprinting methods suggests that $L$. innocua is as closely related to $L$. welshimeri as it is to L. monocytogenes and confirms that there are subtle but consistent genetic differences between the two $L$. ivanovii subspecies and that L. grayi is homogeneous and is validly included in the genus Listeria.

\section{ACKNOWLEDGEMENTS}

We are very grateful to C. L. Gyles for checking the manuscript.

\section{REFERENCES}

1. Bannerman, E., Yersin, M. N. \& Bille, J. (1992). Evaluation of the Organon-Technika MICRO-ID LISTERIA system. Appl Environ Microbiol 58, 2011-2015.

2. Bille, J., Catimel, B., Bannerman, E., Jacquet, C., Yersin, M. N., Caniaux, I., Monget, D. \& Rocourt, J. (1992). API Listeria, a new and promising one-day system to identify Listeria isolates. Appl Environ Microbiol 58, 1857-1860.

3. Boerlin, P., Rocourt, J., Grimont, F., Grimont, P. A. D., Jacquet, C. \& Piffaretti, J.-C. (1992). Listeria ivanovii subsp. londoniensis subsp. nov. Int J Syst Bacteriol 42, 69-73.

4. Boerlin, P., Rocourt, J. \& Piffaretti, J.-C. (1991). Taxonomy of the genus Listeria by using multilocus enzyme electrophoresis. Int J Syst Bacteriol 41, 59-64.

5. Cartwright, C. P., Stock, F., Beekmann, S. E., Williams, E. C. \& Gill, V. J. (1995). PCR amplification of rRNA intergenic spacer regions as a method for epidemiological typing of Clostridium difficile. J Clin Microbiol 33, 184-187.

6. Clayton, R. A., Sutton, G., Hinkle, P. S., Jr, Bult, C. \& Fields, C. (1995). Intraspecific variation in small-subunit rRNA sequences in GenBank. Why single sequences may not adequately represent prokaryotic taxa. Int $J$ Syst Bacteriol 45, 595-599.

7. Collins, M. D., Wallbanks, S., Lane, D. J., Shah, J., Nietupski, R., Smida, J., Dorsch, M. \& Stackebrandt, E. (1991). Phylogenetic analysis of the genus Listeria based on reverse transcriptase sequencing of 16S rRNA. Int J Syst Bacteriol 41, 240-246.

8. Czajka, J., Bsat, N., Piani, M., Russ, W., Sultana, K., Wiedmann, M., Whitaker, R. \& Batt, C. A. (1993). Differentiation of Listeria monocytogenes and Listeria innocua by 16S rRNA genes and intraspecies discrimination of Listeria monocytogenes strains by random amplified polymorphic DNA polymorphisms. Appl Environ Microbiol 59, 304-308.

9. Deng, S., Hiruki, C., Robertson, J. A. \& Stemke, G. W. (1992). Detection by PCR and differentiation by restriction fragment length polymorphism of Acholeplasma, Spiroplasma, Mycoplasma, and Ureaplasma, based upon 16S rRNA genes. PCR Methods Appl 1, 202-204.

10. Ehrenstein, B., Bernards, A. T., Dijkshoorn, L., Gerner-Smidt, P., Towner, K. J., Bouvet, P. J. M., Daschner, F. D. \& Grund- 
mann, H. (1996). Acinetobacter species identification by using tRNA spacer fingerprinting. $J$ Clin Microbiol 34, 2414-2420.

11. Fernandez-Garayzabal, J. F., Suarez, G., Blanco, M. M., Gibello, A. \& Dominguez, L. (1996). Taxonomic note: a proposal for reviewing the interpretation of the CAMP reaction between Listeria monocytogenes and Rhodococcus equi. Int J Syst Bacteriol 46, 832-834.

12. Feresu, S. B. \& Jones, D. (1988). Taxonomic studies on Brochothrix, Erysipelothrix, Listeria, and atypical lactobacilli. J Gen Microbiol 134, 1165-1183.

13. Gürtler, V., Wilson, V. A. \& Mayall, B. C. (1991). Classification of medically important clostridia using restriction endonuclease site differences of PCR-amplified 16S rDNA. $J$ Gen Microbiol 137, 2673-2679.

14. Gürtler, V. (1993). Typing of Clostridium difficile strains by PCR-amplification of variable length 16S-23S rDNA spacer regions. J Gen Microbiol 139, 3089-3097.

15. Gürtler, V. \& Stanisch, V. A. (1996). New approaches to typing and identification of bacteria using the $16 \mathrm{~S}-23 \mathrm{~S}$ rDNA spacer region. Microbiology 142, 3-16.

16. Heyndrickx, M., Vandemeulebroecke, K., Scheldeman, P., Hoste, B., Kersters, K., De Vos, P., Logan, N. A., Aziz, A. M., Ali, N. \& Berkeley, R. C. W. (1995). Paenibacillus (formerly Bacillus) gordonae (Pichinoty et al. 1986) Ash et al. 1994 is a later subjective synonym for Paenibacillus (formerly Bacillus) validus (Nakamura 1984) Ash et al. 1994: emended description of $P$. validus. Int J Syst Bacteriol 45, 661-669.

17. Hookey, J. V., Birtles, R. J. \& Saunders, N. A. (1995). Intergenic 16S rRNA gene (rDNA)-23S rDNA sequence length polymorphisms in members of the family Legionellaceae. $J$ Clin Microbiol 33, 2377-2381.

18. Jannes, G., Vaneechoutte, M., Lannoo, M., Gillis, M., Van Canneyt, M., Vandamme, P., Verschraegen, G., Van Heuverswyn, H. \& Rossau, R. (1993). Polyphasic taxonomy leading to the proposal of Moraxella canis sp. nov. for Moraxella catarrhalis-like strains. Int J Syst Bacteriol 43, 438-449.

19. Jayarao, B. M., Doré, J. J. E., Jr, Baumbach, G. A., Matthews, K. R. \& Oliver, S.P. (1992). Restriction fragment length polymorphism analysis of 16S ribosomal DNA of Streptococcus and Enterococcus species of bovine origin. $J$ Clin Microbiol 30, 2235-2240.

20. Jensen, M. A., Webster, J. A. \& Straus, N. (1993). Rapid identification of bacteria on the basis of polymerase chain reaction-amplified ribosomal DNA spacer polymorphisms. Appl Environ Microbiol 59, 945-952.

21. Jensen, M. A. \& Straus, N. (1993). Effect of PCR conditions on the formation of heteroduplex and single-stranded DNA products in the amplification of bacterial ribosomal DNA spacer regions. PCR Methods Appl 3, 186-194.

22. Kämpfer, P., Böttcher, S., Dott, W. \& Rüden, H. (1991). Physiological characterization and identification of Listeria species. Int J Med Microbiol 275, 423-435.

23. Kathariou, S. \& Pine, L. (1991). The type strain(s) of Listeria monocytogenes: a source of continuing difficulties. Int $J$ Syst Bacteriol 41, 328-330.

24. Kerr, K. G., Rotowa, N. A., Hankey, P. M. \& Lacey, R. W. (1991). Evaluation of the ROSCO system for the identification of Listeria species. J Med Microbiol 35, 193-196.
25. Kostman, J. R., Edlind, T. D., Lipuma, J. J. \& Stull, T. L. (1992). Molecular epidemiology of Pseudomonas cepacia determined by polymerase chain reaction ribotyping. $J$ Clin Microbiol 30, 2084-2087.

26. McClelland, M., Petersen, C. \& Welsh, J. (1992). Length polymorphisms in tRNA intergenic spacers detected by using the polymerase chain reaction can distinguish streptococcal strains and species. J Clin Microbiol 30, 1499-1504.

27. Michel, E. \& Cossart, P. (1992). Physical map of the Listeria monocytogenes chromosome. $J$ Bacteriol 174, 7098-7103.

28. Nesme, X., Vaneechoutte, M., Orso, S., Hoste, B. \& Swings, J. (1995). Diversity and genetic relatedness within genera Xanthomonas and Stenotrophomonas using restriction endonuclease site differences of PCR-amplified 16S rDNA. Syst Appl Microbiol 18, 127-135.

29. Ralph, D., McClelland, M., Welsh, J., Baranton, G. \& Perolat, P. (1993). Leptospira species categorized by arbitrarily primed polymerase chain reaction (PCR) and by mapped restriction polymorphism in PCR-amplified rRNA genes. $J$ Bacteriol 175, 973-981.

30. Rocourt, J., Grimont, F., Grimont, P. A. D. \& Seeliger, H. P. R. (1982). DNA relatedness among serovars of Listeria monocytogenes sensu lato. Curr Microbiol 7, 383-388.

31. Rocourt, J., Schrettenbrunner, A. \& Seeliger, H. P. (1983). Différenciation biochimique des groupes génomiques de Listeria monocytogenes (sensus lato). Ann Microbiol Inst Pasteur 134A, 65-71.

32. Rocourt, J., Wehmeyer, U., Cossart, P. \& Stackebrandt, E. (1987). Proposal to retain Listeria murrayi and Listeria grayi in the genus Listeria. Int J Syst Bacteriol 37, 298-300.

33. Rocourt, J., Boerlin, P., Grimont, F., Jacquet, C. \& Piffaretti, J.C. (1992). Assignment of Listeria grayi and Listeria murrayi to a single species, Listeria grayi, with a revised description of Listeria grayi. Int J Syst Bacteriol 42, 171-174.

34. Sallen, B., Rajoharison, A., Desvarenne, S., Quinn, F. \& Mabilat, C. (1996). Comparative analysis of $16 \mathrm{~S}$ and 23 rRNA sequences of Listeria species. Int J Syst Bacteriol 46, 669-674.

35. Seeliger, H. P. R. \& Höhne, K. (1979). Serotyping of Listeria monocytogenes and related species. Methods Microbiol 13, 31-49.

36. van Belkum A., Kluytmans, J., van Leeuwen, W. \&13 other authors (1995). Multi-center evaluation of arbitrarily primed PCR for typing of Staphylococcus aureus strains. $J$ Clin Microbiol 33, 1537-1547.

37. Vaneechoutte, M., Cartwright, C. P., Williams, E. C., Jăger, B., Tichy, H.-V., De Baere, T., De Rouck, A. \& Verschraegen, G. (1996). Evaluation of $16 \mathrm{~S}$ rRNA gene restriction analysis for the identification of cultured organisms of clinically important Clostridium species. Anaerobe 2, 249-256.

38. Vaneechoutte, M., De Beenhouwer, H., Claeys, G., Verschraegen, G., De Rouck, A., Paepe, N., Ëlaichouni, A. \& Portaels, F. (1993). Identification of Mycobacterium species with amplified rDNA restriction analysis. $J$ Clin Microbiol 31, 2061-2065.

39. Vaneechoutte, M., Dijkshoorn, L., Tjernberg, I., Elaichouni, A., De Vos, P., Claeys, G. \& Verschraegen, G. (1995). Identification of Acinetobacter genomic species by amplified ribosomal DNA restriction analysis. $J$ Clin Microbiol 33, $11-15$. 
40. Vaneechoutte, M., Riegel, P., de Briel, D., Monteil, H., Verschraegen, G., De Rouck, A. \& Claeys, G. (1995). Evaluation of the applicability of amplified rDNA-restriction analysis to identification of species of the genus Corynebacterium. Res Microbiol 146, 633-641.

41. Vaneechoutte, M., Rossau, R., De Vos, P., Gillis, M., Janssens, D., Paepe, N., De Rouck, A., Fiers, T., Claeys, G. \& Kersters, K. (1992). Rapid identification of bacteria of the Comamonadaceae with amplified ribosomal DNA-restriction analysis (ARDRA). FEMS Microbiol Lett 93, 227-234.

42. Welsh, J. \& McClelland, M. (1991). Genomic fingerprints produced by PCR with consensus tRNA gene primers. Nucleic Acids Res 19, 861-866.

43. Welsh, J. \& McClelland, M. (1992). PCR-amplified length polymorphisms in tRNA intergenic spacers for categorizing staphylococci. Mol Microbiol 6, 1673-1680.

44. Widjojoadmotjo, M. N., Fluit, A. C. \& Verhoef, J. (1994). Rapid identification of bacteria by PCR-single-strand conformation polymorphism. $J$ Clin Microbiol 32, 3002-3007.

45. Widjojoadmotjo, M. N., Fluit, A. C. \& Verhoef, J. (1995). Molecular identification of bacteria by fluorescence-based PCR-single-strand conformation polymorphism analysis of the 16S rRNA gene. J Clin Microbiol 33, 2601-2606.

46. Wiedmann-Al-Ahmad, M., Tichy, H.-V. \& Schön, G. (1994). Characterization of Acinetobacter type strains and isolates obtained from wastewater treatment plants by PCR fingerprinting. Appl Environ Microbiol 60, 4066-4071. 